\title{
Nigerian Pluralistic Society and the Relevance of Religious Dialogue as an Instrument of Peace
}

\author{
Ogbole Friday Abu \\ Lecturer (Sociology of Religion and Pentecostal Studies) \\ (Department of Religious Studies, Faculty of Arts and Social Sciences, \\ Gombe State University, Gombe, Nigeria) \\ Phone No:08036382200, E-mail: foabu@yahoo.com \\ Ogunrinade Adewale O. (Ph.D.) \\ Senior Lecturer (Church History with specialty in African Christianity) \\ (Department of Religious Studies, Faculty of Arts and Social Sciences, \\ Gombe State University, Gombe, Nigeria) \\ Phone No: 08035522497, E-mail: walesoft@yahoo.com
}

\section{Doi:10.5901/jesr.2013.v4n3p343}

\section{Abstract}

Nigeria being a multi-religious state is currently bedeviled with a lot of crises which range from political and religious to socioethnic problems. This paper identifies Nigeria as religiously pluralistic and the importance of engaging in dialogue to surmount its myriad problems and process and achieve the needed peace. However, much emphasis is laid on the two major religions in Nigeria namely Christianity and Islam. The paper identifies the forms of dialogue and how it could be engaged in the polity, possible areas of dialogue, principles of dialoguing and the obstacles that may be encountered in the course of doing so. The paper recommends that for effective dialogue to take place among all religions, misconception, stereotype and bias should be eliminated. It further recommends that effective dialogue between the two major religions in the country should be effectively enhanced to ensure peace.

\section{Introduction}

In pre-modern period there was relatively little contact between peoples in relation to exposure to other cultures. The gods they worshipped and the beliefs they shared were largely unquestioned from within and outside the perimeters of their boundaries. Pre-modern societies were ideologically regulated within themselves. Beliefs and practices were intimately recognized and adhered to in the total configuration of society. Until now most racial and religious groups in the entire world remain concentrated in their homelands. But with globalization today, almost every country of the world has become multi-racial and multi-religious. This also means that no community can any longer live in isolation from others; even countries that closed their doors against foreign values now have no choice since pluralism enters through migration, travel, trade, the media and the internet (Jorgen, 2000).

The effect of pluralism on our contemporary society is felt more than ever, especially with the scientific and industrial revolutions coupled with the competing number of worldviews available to us. Despite the problems posed to us by the contemporary pluralistic society, the resurgence of political radicalism motivated by religion and expressed in religious terms in the last couple of decades has spread renewed awareness and experience of destructive inter-religious relations among peoples in all continents of the world. It is in reaction to such that movements for inter-religious dialogue have gained a growing support. During the 1960's and 70's the World Council of Churches and the Vatican embarked on major moves towards inter-religious dialogue.

The question then is how can members of a pluralistic society enjoy peaceful co-existence and to what extent can dialogue help? This paper attempts to look into the problems encountered in the pluralistic society, examines different types of dialogue, including dialogue in the Nigeria society and possible fresh areas of dialogue. The paper also discusses principles of dialogue as well as impediments to dialogue in a pluralistic society. Finally it provides some recommendations. 


\section{Pluralism and the Pluralistic Society}

The concept of pluralism can be seen from diverse points of view, but for the sake of this paper, it won't be out of place to look at the term holistically and then narrow it to our interest. Pluralism is a framework of interaction in which groups show sufficient respect and tolerance of each other and they fruitfully co-exist and interact without conflict or assimilation. It is undoubtedly one of the most important features of modern societies and social groups, and may be a key driver of progress in science, society and economic development.

In a lecture of $15^{\text {th }}$ May 2005 on Religion and the Pluralistic Society delivered by Cyril Imo, pluralism is the result of social transformation which gives rise to people of different beliefs, values and customs being brought together by the force of history in social relationship. This is why Thomas Mason tries to differentiate between the pre-modern society as ideologically homogenized within itself and a new cultural world as a world of increasing variety becoming in important respects a more unified, constricted and congested world in the making ( Thomas, 1989). The pluralistic society also means a certain diversity of value and interests, which might even be stepping on each other because of the competing number of worldviews available to individuals or group of individuals which has generated lots of problem among adherents especially the two exclusivist religions, Christianity and Islam whose claim to absolute truth cannot be compromised. It is important to examine religious pluralism so as to have a good background and deeper understanding of this issue.

\section{Religious Pluralism and Dialogue}

A kind of Religious pluralism existed in the Indian subcontinent when the Hindu Veddas was established around 2500 BC. Other faiths were later established such as Shramana, Jainism, Buddhism, Zoroastrianism, Islam and Christianity. In Japan, Buddhism and Shintoism had coexisted before the emergence of Christianity. Christianity came because of the coming of the British colonialist regime which lasted until 1947 and increased conversions to Christianity among the low caste Hindus.

The rise of religious pluralism in the modern West is closely associated with reformation and enlightenment. Religions like Judaism and Islam had existed alongside Christianity in many parts of Europe, but they were not allowed the same freedom as granted to the orthodox denominations. New forms of Christianity were suppressed by force. Early forms of Protestantism attempted to acquire the same privileges as those previously claimed by Roman Catholicism in protestant England, Scotland and the Ireland. There were severe legal and social restrictions on Jews and Roman Catholics until the passing of Catholic Emancipation Act which was a statute of the British Parliament in 1829 granting full political and civil liberties to Roman Catholics in Great Britain and Ireland

Similar restrictions on small protestant sects who disagreed with the national churches in these countries prompted such groups as the Pilgrim Fathers to seek freedom in North America, although many historians have noted that when these groups became the majority they sometimes sought to deny this freedom to Jews and Roman Catholics. However, protestant and free thinking philosophers like John Locke and Thomas Paine, who argued for tolerance and moderation in religion, were strongly influential on the founding fathers. The modern religious freedom and equality underlying religious pluralism in the United States are guaranteed by First Amendment to the United States constitution, which states; "Congress shall make no laws respecting an establishment of religion, or prohibiting the free exercise thereof... in the united states. Therefore, Religious Pluralism can be said to be overseen by the secular state, which guarantees equality under law between different religions, whether these religions have a handful of adherents or many millions. The state also guarantees the freedom of those who choose not to belong to any religion (Hutchison, 2003). This America's model is not different from Section 10 of Nigeria's constitution which states that the government of the federation or of a State shall not adopt any religion as State Religion (Ostien \& Gamaliel 2004).

Freedom of religion encompasses all religions acting within the law in a particular region, whether or not an individual religion accepts that other religions are legitimate or that freedom of religious choice and religious plurality in general are good things. Many religions in the United States, for example, teach that theirs is the only way to salvation and to religious truth, and some of them would even argue that it is necessary to suppress the falsehoods taught by other religions.

Religious pluralism refers to a situation where there exists a different religious persuasion within a given institutional frame. In effect, a religious pluralistic society is a multi religious society, where the different religious groups have different doctrines of salvation and world views which eventually condition the style of life, values and ultimate goal of each group (Beneke, 2006). 
However, there can be no religious pluralism where there is no freedom of religion. This implies that the only platform for religious pluralism is freedom of religious expressions and practices. Different religion must then acknowledge the fact that they need each other and that is why dialogue is very crucial in a religiously pluralistic society. For us to reach a situation where we can respect ourselves and the values highly honored by others without having to give up our values, which we respect in a religiously pluralistic society, dialogue is therefore indispensable. Dialogue is part of the living relationship between people of different faiths and ideologies as they share in the life of the community.

According to H.A. Mukti, (2002)

Dialogue is a process in which individuals and groups learn to wipe out fear and distrust of each other and to develop new relations based on mutual trust. A dialogue is a dynamic contact not only between one rational being, but between life and life. A dialogue is directed towards living together, acting together, building the world anew together.

It is also useful for all mankind to see dialogue as an invitation to reject ignorance, arrogance and pride. It is an invitation to break through our isolation, our self-centeredness and our self-sufficiency, it is an invitation to recognize and accept the other. It is an invitation to live life responsibly, which implies being in dialogue with my neighbors, with the creation and with God. This is an essential element of every religion.

Although significant experience has been gained in Christian Muslim dialogue, misconceptions, stereotypes and biased attitudes still prevail. This indicates that dialogue between Christians and Muslims need to be strengthened. Knowing one another is an important component of dialogue. Mutual knowledge contributes to mutual understanding. We should not limit our knowledge about one another to only the facts of our faith. It is vital to take into consideration the living encounters of the people at different levels of society. Through this we deepen our mutual knowledge and face our uncertainties and a fear with confidence because there are different people with different cultures and world views, as such there is an urgent need for dialogue (Mukti, 2002).

\section{Forms or Types of Dialogue}

The catholic secretariat for non Christians in the Vatican has rightly observed that dialogue can take on many different forms according to the purpose for which we meet one another and according to our own personal characteristics and dispositions.

The secretariat identifies the following forms of dialogue such as Occasional Dialogue consisting of sporadic encounters resulting from the politeness and affection of the people concerned and Professional Dialogue as between people who engage in a common enterprise. Cultural Dialogue is a meeting of cultures according to the laws of acculturation while Doctrinal dialogue is an exchange of doctrinal views. Political dialogue is the type involved with exchange of political matters and Social Dialogue is about exchange of views on social situations. Religious Dialogue however deals with exchange of religious views by various adherents.

Pope John Paul II in his message for the celebration of the day of peace on the $1^{\text {st }}$ January, 1983 declared that for peace to reign in the world over there must be dialogue both at national and international levels. Accordingly, when dialogue between a government and its people is absent, social peace will be threatened or absent. It is like a state of war. Example of many countries shows that an effective and fruitful dialogue is possible not only between Government and its people, but between the various cultural social, ethnic and religious groups within the nation. Honest and patient dialogue also produces results on the international level. He further maintained that this dialogue must be based on the strong conviction that the good of a people cannot be finally accomplished against the good of another people; all have the same rights, the same claims to a worthy life for their citizens. The object of such international dialogue must be concerned with the rights of man, with justice between peoples, with economics, with disarmament, and with the common international good.(Catholic Secretariat for Non Christians in the Vatican)

\section{Dialogue in the Nigerian Society}

The need for dialogue in Nigeria is an urgent one, especially among religious groups. Emphasis is laid much on religious groups due to ill-fated occurrences in recent years. In recent times, there have been clashes among adherents of Islam and Christianity in Nigeria. However, the conflict is not restricted to Christians and Muslims alone as adherents of African Traditional Religion are also not left out. There are cases of clashes between adherents of Africa Traditional Religion and other religious groups.

These clashes happen in several areas, for example one of the authors who is from Otukpa, in Ogbadibo LGA among the Idoma speaking people of Benue state and who has witness many of such incidence states that non 
adherents of traditional religion usually do not agree with traditional burial rites. Adherents of African Traditional Religion who are those to carry out the burial rites believe that at the death of an elder in the village after the initial burial of the corpse, a date will be fixed for the second burial, which they consider as the main burial. Christians in the family however consider this as ancestral worship and will not want to associate themselves with it.

In the south eastern part of Nigeria some women are often accused of killing there husbands and have had to go through certain traditional practices at the death of their husbands which Christians often condemn, for example drinking water used to bath the corpse of the husband to prove their innocence or placing a cola nut on corpse of the husband and asking her to eat in other to prove her innocence (Fasoranti \& Haruna, 2012). These and many more are some of the major areas of conflict among the major religious groups in Nigeria which require urgent attention so that the future of this country and the world at large can be secured for us and for posterity. In a pluralistic society like Nigeria, it is very evident that there must be clash of interest among adherents of different religious groups but since all the religions of the world preach peace and love, such conflicts need to be curtailed at all cost, but this is not possible where there is no dialogue.

As Ilori ( 2001) rightly pointed out; both Christianity and Islam in their recognition and adoration of God share a monotheistic tradition. They also recognize many points of theological and spiritual convergence including reverence for Jesus. The adherents of both religions therefore have cause and ground for mutual recognition, respect and cooperation. They are particularly united in their common cherishing of the religious and moral values for which their respective traditions are distinguished. They are also one in their common experience of the challenges with which materialism and modernism have posed to religious and moral values. Adherents of both religions ought to share their concern and understanding, not in an attempt to forge an alliance against anyone but as a sign of their witness to God.

In sharing together the understanding and experiences of the world in which they live, the Christians and Muslims should work together to try to build the world in accordance with the will of God as understood by their respective religious traditions. This means a common involvement in the concerns and interest of their societies where the two religions are closely intertwined with social events. Professions of God's sovereignty over all things and the duty to submit to God should be strengthened by a corresponding willingness to strive for mutual awareness and caring.

Furthermore, there is need for dialogue between Christians and Muslims and this is very feasible. For example, the world wide problems of human suffering due to poverty, wars and political oppression are so vast and pervasive that no one faith group can solve them, yet tension between Muslims and Christians often prevent co-operation in solving these urgent human problems.

Most people today live out their lives in actual community with people who may be committed to faith and ideologies other than their own. They live in families sometimes of mixed faiths and ideologies; They also live as neighbors in the same towns and villages. They need to build up their relationships to express mutual human care and search for mutual human understanding. This sort of dialogue is very practical and is concerned with problems of modern life - the social, political economic and above all, the family. These concerns which is beyond the local requires Christians and Muslims to engage in dialogue towards the realization of a wider community in which peace and justice may be more fully realized. This in turn leads to a dialogue between communities, in which issues of national and international concerns are tackled.

Dialogue can be recognized as a welcome way of obedience to the commandments of the Decalogue "you shall not bear false witness against your neighbor (Ex. 20). It helps not to disfigure the image of the neighbors of different faiths and ideology. It has been the experience of many people that the dialogue between Christians and Muslims is indeed possible on the basis of mutual trust and respect for the integrity of each participant's identity. Dialogue therefore is a fundamental part of service within the community. In dialogue people actively respond to the command to love God and their neighbors as themselves. Dialogue is a joyful affirmation of life against chaos and participation with all who are allies of life in seeking the provisional goals of a better human community. This dialogue is not a secret weapon in the armory of an aggressive religious, militancy. Rather it is a means of living one's faith in service of community with ones neighbors.

Dialogue between Christians and Muslims is necessary and should be established and encouraged at various levels such as: the specific historical roots which the two religions have in common, the attitude of self -criticism which is inherent in each religion. Other levels are the increased mobility and mixing of populations which has made meeting of Christians and Muslims much more common, and has increased the responsibility of the two religions to find ways of living together in the same society and lastly the special present situation especially the common responsibility of both religions with regard to the political problems in Nigeria in particular and Africa in general.

The African Traditional Religion adherents and leaders should be prominently involved in our concern for peaceful co-existence especially now that they seem to be gaining international recognitions. At the local level it is very important 
to dialogue with them properly and to make them know that religion is not forced on people and that every individual have right to religion of his or her choice. At this point we shall look at possible areas of effective dialogue.

\section{Possible Areas of Dialogue}

It is evident that Christians and Muslims in Nigeria have been involved in hostility which to a large extend have crippled their relationship. This has shown the world the gap that exists between them despite their common roots. It is however possible to close up these gaps by taking certain steps to create areas of dialogue among religious adherents, this means that there should be variety of situations in which adherents of religion live, talk, think and work together. Methods of doing this are through exchanging Goodwill messages during religious feast such as Ramadan, Eid Fitr, Eid Maulud, Christmas, Easter, Harvest and festivals. For instance, Christians could welcome a Muslim message at Ramadan which emphasis the spirit of sacrifice and self denial and urges the need for serving the interest of others in the community. Muslims could also appreciate a Christian message at Easter which expresses how suffering and sacrifice can be instrumental to healing and reconciliation in the community. Information exchange about important events in each part of the community could further increase mutual trust and widen areas of credibility. Christian Association of Nigeria (CAN) and Jama'atu Nasril Islam (JNI) could work together (Alabi, 2002).

\section{Principles of Dialogue}

In a pluralistic Society like Nigeria where different world views are clamoring for attention, there is bound to be conflicts, people have spiritual and moral obligations to relate with each other in mutual respect. They must accept a common God given responsibility to work for peace through dialogue. The following are some of the principles for effective dialogue. Truthfulness; in dialogue each should be truthful in his motive to his fellows and to God. This truthfulness could help to remove complacency, suspicion or unspoken fears. Mutual respect is another necessary principle for dialogue. This does not involve a stale co-existence of "live, and let live", but a sensitive regard for the partner's sense of right and wrong and conviction, sympathy for his difficulties and an admiration for his achievements. There should be no offensive comparison of strength in one tradition with weakness in the other. There should be drawing upon the riches of the scriptures, doctrines and traditions of religions in promoting good relationships and effective dialogue with each other.

There should be an awareness of the suspicions which surround dialogue in the minds of some religious adherents.

The process of dialogue calls for patience, generosity and courage. Both must strive to overcome stereotypes and bias, they must try to overcome ignorance, misunderstandings, and the falsifications, and caricatures of each other's faith which are seen in the mass media and textbooks. Dialogue should be understood as a readiness to learn as well as to share information, to receive as well as to give.

For effective dialogue, both Christians and Muslims should recognized that it is their duty and right to reduce areas of misunderstanding between respective communities, themselves and others and at all times affirming the integrity and dignity of human beings. Both should affirm that all human relationships should point to God as the beginning and end of all things.

Through dialogue, we grow in faith. Involvement in dialogue brings about constant re-appraisal of our faith and understanding of our theological traditions. Dialogue drives all communities to self-criticism and re-thinking the ways in which they have interpreted their faith traditions. It brings about change in the experience of faith, helping people to deepen and grow in their faith in unexpected ways. In dialogue we affirm hope in the midst of the many divisions, conflicts, and violence. There is hope that it is possible to create a human community that lives in justice and peace. Dialogue is not an end in itself. It is a means of building bridges of respect and understanding. It is a joyful affirmation of life for all.

In dialogue we nurture relations. Building bonds of relationship with those considered "the other" is the goal of all dialogues. However, such bonds are not built easily or quickly. Therefore patience and perseverance are crucial in the practice of dialogue. The tenacity to go on, even when the fruits are not obvious, is one of the basic disciplines of dialogue. In dialogue we must be informed of the context. Dialogue takes place in concrete settings. Awareness of such realities as historical experience, economic background and political ideologies is essential. Further, differences in identity such as culture, gender, generation, race and ethnicity also have an important impact on the nature and style of interaction. 
The purpose of dialogue, once the context is taken seriously, is not to remove or run away from differences but to build confidence and trust across them. In dialogue we strive to be inclusive, since dialogue can easily

become an elitist activity and be confined to certain strata of society, care should be taken to ensure that dialogue takes place at different levels, between different groups and on subjects that affect the lives of all sections of the community (WCC).At this point it will be important to examine some of the impediments to dialogue in a pluralistic society.

\section{Impediments to Effective Dialogue}

Dialogue as a means to an end among peoples of different faith also has it's own problems, few of these problems will be discuss as follows: We are aware that this task (i.e. dialogue) entails a critical and self-critical assessment of our religious traditions, So as to bring into full light what is in them is conclusive to the achievement of community beyond the frame of the particular grouping, without minimizing the beliefs, doctrines' and rites which establish the peculiarity of each tradition. But before we come to claim these resources we must admit that there are many obstacles in our way. It is one of the tragedies of humanity that it can be precisely the striving for world community, expressing itself in various beliefs, which prevents the realization of this community here and now. A common way must be found, while honoring the absolute claims of each concerning the world order. Fear of the other is the major impediment to genuine dialogue. Where the other is seen as a threat to one's own group or personal identity, dialogue can only be inhibited and the temptation to self -justification and self -advertising may become too strong. Minorities may be afraid of being overwhelmed or absorbed by the larger community that it encounters in dialogue. Dissenting groups may be afraid of entering into dialogue with exponents of the ideology of the ruling group.

Ethnic or radical groups may sometimes need to refuse dialogue in order to affirm their distinctive identity. In other cases an invitation to dialogue may be an occasion for affirmation of the identity of a generally unrecognized group. Some fears are more rational than others. Quite often genuine fears may be expressed in terms of rationalizations. The absence of a central control and interpretation of various Holy books of the different religions constitute an obstacle to effective dialogue. There is virtually no religion in the world that have absolute control of it's members in the area of uniform interpretation of scriptures and theology, but what we find today is breakaways resulting in different denominations and sects with ideologies and interpretations differing from the orthodox practice (Alabi, 2002).

The perception of adherents of the various religions in Nigeria in relation to western culture could hinder effective dialogue. For instance certain western practices accommodated in Christianity are considered immoral in other religions. Examples of such practices are Kissing, shaking and hugging the opposite sex. Some adherents of the different religions in Nigeria believe that engaging in dialogue is a betrayal of faith. It will be desirable if dialogue is meaningfully engaged among adherents of various religions so as to achieve progress. With meaningful dialogue people see one another as one willing to work together for the common good of mankind. With information technology where news are easily disseminated, people are easily exposed to bad news especially does of other religions and thereby creating an obstacle to effective dialogue.

\section{Recommendations}

This paper recommends that misconception, stereotypes and bias attitudes should be avoided in order to engage in meaningful dialogue. Engaging in meaningful dialogue involves knowing one another and having mutual knowledge of our corporate existence. We should not limit our knowledge about one another to only the fact of our faiths. Rather, the living encounters of the people at different levels of society should be considered and encouraged. If these are observed, mutual knowledge about man's challenges and limitations would be understood and appreciated better. For example, during the 2001crisis in Jos, Christians and Muslims helped one another in Dadin Kowa and Zarmaganda areas of Jos. They provided security by monitoring intruders and road blocks.

Inter-religious dialogue will increase the efficacy of evangelism in any religion when the belief and practices of other religion are clearly understood. Adherents can more effectively identify the ways in which their religion can be presented without causing religious tension. Phan, (2012) caution that inter religious dialogue is not to unite all the world religions into some sort of global religion. Rather it is first of all preventing religion from becoming a source of violence and hatred to remove mutual misunderstanding and prejudices and to promote a greater appreciation of the various religious traditions. 
Finally, encounters with other religions will increase the appreciation that Christians and Muslims have for their faith. This can inspire both faith to address concerns and weakness in their local churches and Mosques, resulting in increased retention of members.

\section{Summary and Conclusion}

This paper largely discusses dialogue in a pluralistic society with specific interest on Nigeria. It also examines religious pluralism and different forms of dialogue, the need for dialogue in the Nigerian society and some possible areas of dialogue. Principles of dialogue and some basic impediments to dialogue in a pluralistic society where also examined. In conclusion, no nation however blessed can advance in the face of chaos and conflict stemming from ethnic, moral and religious backgrounds. If the nascent -democracy in Nigeria must be truly sustained, everyone must work together in peace, unity of heart and purpose to nurture it to its realization.

\section{References}

Alabi, T.(2002). Religious Conflicts in Northern Nigeria. A Critical Analysis of Paper at International Conference on the Assessment of Nigeria's Democracy Journey so Far". Organized By Centre for Advance and Social Sciences (CRASS), 2002

Beneke, C. (2006). Beyond Toleration: The Religious Origins of America Pluralism. New York, NY: Oxford University Press.

Cyril O. Imo, Religion and the Pluralistic Society Lecture of 5 May 2005, Postgraduate class of 2005, Department of Religious Studies, University of Jos.

Etannibi Et al.eds. (2002) Ethno-Religious Conflicts and Democracy in Nigeria:Challenges. Kaduna: Human Rights Monitor.

Hutchison, W. R (2003) Religious Pluralism in America: A continuous History of a Founding Ideal. New Haven: Yale Press.

Jorgen, S. N. "The contribution of Interfaith Dialogue Towards A Culture of Peace" A paper presented at the International Conference on Dialogue of Civilizations, Institute of Islamic Studies, London 27th October 2000. Available from www.google.com on the on the $14^{\text {th }}$ November 2013

Joseph, I. (2001). Moral Philosophy in African Context, Zaria: Adeniji Press.

Fasoranti, 0.0 \& Aruna, .J O. (2012) A Cross Cultural Comparison of Practice Relating to Widowhood and Widows Inheritance among the Igbo and Yoruba in Nigeria. Journal of World Anthropology. Vol. 3, No. 1. 60. 2012. Web. 20 January, 2013.

Joseph A. I. Dialogue between Christians and Muslims in Nigeria: How Feasible. A paper presentation. Occasional paper presented at the Department of Christian Religious Studies Education, Ahmadu Bello University, Zaria 1996.

Mukti, A. H. A. Rligions, Nations and the Search For a world Community Christian Muslim Dialogue. P. 19. Edited by Samartha S.J. and Taylor J.B.

Ostien, P. \& Gamaliel, J.D. (2004). The Law of Separation of Religion and State in the United State: A Model for Nigeria? S.0.0, Amali et al. eds. Religion in the

United States: Ibadan American Studies Association of Nigeria 2002. Resolution and Transformation, Ibadan: Spectrum Books.

Phan, P. (2012). Interreligious and Ecumenical Dialogue at the Vatican II: Some Rethinking Required. Conversation on Jesuit Higher Education: Vol.42, Article 2012. Web. 14th January, 2013.

Thomas F. M. (1989). Toward A philosophy of Pluralism. A paper presented at the Occasional seminar organized by the Department of Religious Studies University of Jos, 1989. 
